\title{
Increased Activity of Interleukin-6 but not Tumor Necrosis Factor- $\alpha$ in Lung Lavage of Premature Infants is Associated with the Development of Bronchopulmonary Dysplasia
}

\author{
ALAKANANDA BAGCHI, ROSE M. VISCARDI, VICKI TACIAK, JEFFERY E. ENSOR, \\ KIMBERLEY A. MCCREA, AND JEFFREY D. HASDAY \\ The Division of Neonatology, Department of Pediatrics [A.B., R.M.V., V.T.] and the Division of \\ Pulmonary and Critical Care Medicine, Department of Medicine [J.E.E., K.A.M., J.D.H.], \\ University of Maryland School of Medicine, Baltimore, Maryland 21201
}

\section{ABSTRACT}

\begin{abstract}
Although considerable evidence suggests that bronchopulmonary dysplasia (BPD) is the result of prolonged inflammation and impaired healing of the immature lung, the mediators that regulate inflammation in neonatal lung injury have not been completely elucidated. We examined whether the cytokines IL- 6 and tumor necrosis factor- $\alpha$ (TNF) interact to modulate a cascade of cell-cell signaling events involved in inflammation contributing to the development of BPD. To determine the relative activities of these cytokines in neonatal lung injury, lung lavage samples were serially obtained from 1 to $28 \mathrm{~d}$ from 11 infants with self-limited respiratory distress syndrome (RDS), 19 infants with evolving BPD, and 10 control infants ventilated for nonpulmonary reasons. On the first day of life, there were no differences in antigenic IL-6 concentrations in lavage fluids among the BPD, RDS, and control groups, but IL- 6 activity determined by the 7TD1 proliferation assay was 15-fold and 6.6-fold higher in lung lavage of infants who developed BPD compared with activities in lavage from control and RDS infants, respectively (control,
\end{abstract}

$49.4 \pm 17.6 ;$ RDS, $117.3 \pm 59.6 ; \mathrm{BPD}, 779.5 \pm 212.6 \times 10^{3}$ hybridoma units/L, mean $\pm \mathrm{SEM}, p=0.02$ ). This suggests that pathways for inactivating or inhibiting IL-6 that may be present in the lungs of RDS and control infants may be deficient in BPD infants. IL-6 activity remained elevated in lavage of BPD infants for the first 2 wk and declined to low levels by $\mathrm{d} 28$. There were no differences among groups on the first day of life for TNF antigen concentration or TNF activity determined by the L929 bioassay. Detectable but low TNF activity was found in BPD samples, with peak activity found in d-14 samples. Differences in complex interactions among these and other cytokines with their receptors and inhibitors may predispose some infants with RDS to develop BPD. (Pediatr Res 36: 244-252, 1994)

$\quad$ Abbreviations
RDS, respiratory distress syndrome
BPD, bronchopulmonary dysplasia
TNF, tumor necrosis factor- $\alpha$
PROM, prolonged rupture of membranes

and in primate models of acute lung injury (7), there is a rapid influx of neutrophils into the lung during the first 48 to $96 \mathrm{~h}$ after initial injury followed by an increase in alveolar macrophages with subsequent resolution of airway inflammation. In contrast, in infants who develop BPD, the neutrophil influx is prolonged and the alveolar macrophage entry is delayed and blunted (5). Early differences in inflammatory cell recruitment and activation may contribute to the pathogenesis of BPD in susceptible infants.

Although several biochemical abnormalities have been described in BPD, including an imbalance of elastase $/ \alpha_{1}$. proteinase inhibitor $(6,8-11)$, increased levels of plateletactivating factor (12), and depressed intraalveolar fibrinolysis (13), the mediators that regulate neonatal lung
Correspondence and reprint requests: Rose Marie Viscardi, M.D., Department Pediatrics, University of Maryland Hospital, N5W68, 22 S. Greene St., Baltimore, MD 21201.

Supported by the National Institutes of Health Grants R2914L44853 (R.M.V.) and R29CA52741 (J.D.H.) and a Veteran Affairs Research Associate Award 128-4284-0003 (J.D.H.). 
injury in patients with BPD have not been completely elucidated. There is now considerable experimental evidence that the inflammatory cascade initiated by acute injury in the adult lung is mediated by the release of cytokines (14). These multifunctional polypeptides are important in coordinating the host immune response to infection and tissue injury (14). Previous studies reported increased concentrations of the cytokines TNF and IL-6 in amniotic fluid of women with preterm labor complicated by intraamniotic infection $(15,16)$ and in plasma of newborns with sepsis (17). Although functional IL-6 activity was not measured, IL-6 antigen concentrations were elevated on $d 1$ in lung lavage of intubated infants after PROM with or without neonatal sepsis (18).

The major effects ascribed to IL-6 involve upregulation of the local immune response, but recent evidence demonstrating that direct intratracheal instillation of IL-6 abrogates subsequent lipopolysaccharide-induced lung injury suggests that IL-6 may also exert important antiinflammatory effects in the lung (19). This study and others (19-21) demonstrated that the antiinflammatory effects of IL- 6 are caused, in part, by the inhibition of TNF synthesis and TNF-induced cytotoxicity. Because of this potential feedback interaction of TNF and IL-6, these two cytokines may be important modulators of the inflammatory response.

The goals of this study were 1 ) to determine whether the development of BPD is associated with changes in local pulmonary TNF and IL-6 during the first month of life and 2) to compare the activities and antigen concentrations of these cytokines in lung lavage from control infants without pulmonary disease, infants with selflimited RDS, and infants who develop BPD. Because the control and RDS infants were intubated for shorter periods than the BPD infants and only intubated infants could ethically be lavaged, comparisons among the three groups were limited to the first day of life. We measured functional activities and antigen concentrations of these cytokines in serially obtained lung lavage from 19 preterm infants who developed BPD, 11 infants with limited RDS, and 10 control infants. We proposed that, in the development of BPD, IL-6 and TNF interact to modulate a cascade of cell-to-cell signaling events involved in the inflammatory response. We hypothesized that differences in the activities of these cytokines may predispose some infants with RDS to develop BPD.

\section{METHODS}

Rabbit anti-human TNF antiserum was provided by Dr. Steven Kunkel (University of Michigan). Recombinant human IL-6 was expressed from plasmid pT7.71 hIL-6 in Escherichia coli BL21 (DE3) (American Type Culture Collection, Rockville, MD) and was purified by diethylaminoethanol-cellulose chromatography (22). Rabbit anti-human IL-6 antiserum was prepared by immunizing female New Zealand White rabbits (Hazelton, Hazelton, PA) with $500 \mu \mathrm{g}$ of IL-6 in complete Freund's adjuvant s.c. and boosting with $500 \mu \mathrm{g}$ of IL-6 i.v. $10 \mathrm{~d}$ before bleeding. Serum was collected from clotted blood by centrifugation and revealed three bands of 23 to $26 \mathrm{kD}$ on Western blots of recombinant human IL-6. This antiserum neutralized the mitogenic activity of recombinant and natural IL-6 in the 7TD-1 bioassay.

Study population. Lung lavage was serially obtained from 30 premature infants admitted to the University of Maryland neonatal intensive care nursery who met the following criteria: 1) gestational age $<33 \mathrm{wk}$; 2) birth weight appropriate for gestational age; 3 ) requirement for mechanical ventilation on the first day of life for respiratory distress; 4) diagnosis of RDS confirmed radiographically; and 5) absence of documented infection or congenital lung abnormalities. Lung lavage was also obtained from 10 control infants who were intubated and mechanically ventilated for nonpulmonary reasons (apnea, 4; duodenal atresia, 1; abdominal wall defects, 3; and transposition of the great vessels, 2). The study protocol was approved by the institutional review board of the University of Maryland at Baltimore, and parental consent was obtained for each subject.

A subject was considered to have progressed to BPD if the infant developed the following: 1 ) required fraction of inspired oxygen $>0.21$ on $\mathrm{d} 28$ to maintain arterial $\mathrm{PO}_{2} \geq$ $6.65 \mathrm{kPa}(50 \mathrm{~mm} \mathrm{Hg})(23)$ and 2) $\geq$ stage III radiograph according to Northway's classification (24). Although the criterion of oxygen dependency at $28 \mathrm{~d}$ probably overestimates the diagnosis of BPD, an $x$-ray classification of $\geq$ stage III BPD is strongly correlated with typical BPD lung pathology (25).

Lung lavage. Subjects' lungs were lavaged with two $1.0-\mathrm{mL}$ aliquots of sterile saline using a standardized technique (13) on $d 1,3,5,7,14,21$, and 28 as long as the infant remained intubated. While the infant was supine with the head midline, $1.0 \mathrm{~mL}$ of sterile saline was instilled endotracheally, three to five breaths were delivered with a Laerdal self-inflating resuscitation bag (Laerdal Medical Corp., Armonk, NY) or ventilator, the endotracheal tube was suctioned using a 6.5 or 8.0 French catheter, and the lavage was collected into a sputum trap. Suctioning was repeated with the head turned to one side and then the other. The procedure was repeated with a second $1.0-\mathrm{mL}$ saline instillation. The suction catheter was rinsed with $0.5 \mathrm{~mL}$ of saline. The mean volume recovered from the lavage procedure was $0.58 \pm 0.05 \mathrm{~mL}$. Lavage samples were collected on $\mathrm{d} 1$ between 10 and $24 \mathrm{~h}$ of life. The lavage samples were kept on ice until processed. Specimens were centrifuged at $2000 \mathrm{rpm}$ for $10 \mathrm{~min}$ at $4^{\circ} \mathrm{C}$. The supernatant was removed and stored at $-70^{\circ} \mathrm{C}$. Cells were counted using a hemacytometer, and cell viability was assessed by trypan blue dye exclusion. Cytospin preparations were made and stained with Diffquick (Baxter Healthcare Corp., McGraw Park, IL), and cell differentials were determined.

Pulmonary function. Serial pulmonary functions were determined using a computerized system (Pulmonary Evaluations and Diagnostic System; Medical Associated 
Services, Inc., Hatfield, PA) on the same days as the lung lavage. An esophageal balloon placed in the distal third of the esophagus was connected to a differential pressure transducer (Celesco P7D; Celesco Transducer Products, Inc., Canoga Park, CA). A pneumotachograph (Fleisch $00)$ was placed in the ventilatory expiratory circuit, and transpulmonary pressure and inspiratory and expiratory flow were measured. Tidal volume, dynamic compliance/ $\mathrm{kg}$, and pulmonary resistance were calculated using the software of the Pulmonary Evaluations and Diagnostic System (26).

7TD-1 bioassay for $I L-6$. Functional IL-6 activity was determined by measuring proliferation of the IL-6dependent cell line 7TD-1 (27). Serial 2-fold dilutions of samples or recombinant human IL- 6 were plated with $4 \times$ $10^{3}$ 7TD-1 cells/well (American Type Culture Collection) in sterile 96-well flat-bottom microtiter plates (Costar, Cambridge, MA). After incubation for $72 \mathrm{~h}$, cell viability was determined by metabolism of 3-(4,5-dimethylthiazol2-yl)-2, 5-diphenyltetrazolium bromide (MTT, Sigma, St. Louis, MO) to a blue formazan product that was solubilized by incubation with $100 \mu \mathrm{L} /$ well of a solution containing $20 \%$ (wt/vol) SDS in $50 \% \mathrm{~N}, \mathrm{~N}$-dimethylformamide (Sigma), pH 4.7, for $2 \mathrm{~h}$. The absorbance at $570 \mathrm{~nm}$ was measured using a microplate reader (Biotek Instruments, Winooski, VT). IL-6 activity was calculated from a standard curve using the Parlin data-fitting program and was expressed as hybridoma units/L (28). In selected experiments, samples were preincubated with anti-IL-6 antiserum or preimmune serum for $1 \mathrm{~h}$ at room temperature before assay.

L929 bioassay for TNF. Functional TNF activity was determined by measuring cytotoxicity for TNF-sensitive L929 cells (29). L929 cells (American Type Culture Collection) were plated into 96 -well flat-bottom microtiter plates (Costar) at a concentration of $6 \times 10^{4}$ cells/well in CRPMI $/ 10 \%$ newborn calf serum containing $1 \mu \mathrm{g} / \mathrm{mL}$ actinomycin D (Sigma). Serial 2-fold dilutions of samples or recombinant TNF standard (Genzyme Corp., Cambridge, MA) were added in triplicate to the plates. After $18 \mathrm{~h}$ of incubation at $37^{\circ} \mathrm{C}$, the monolayers were washed, fixed with methanol, and stained with $0.1 \%$ crystal violet, and the absorbance at $540 \mathrm{~nm}$ was measured on a microtiter reader. One unit of TNF activity caused $50 \%$ lysis of L929 monolayers (29).

ELISA. ELISA for IL-6 and TNF were performed using commercially available kits purchased from Genzyme Corp. and Endogen (Boston, MA), respectively. These assays had sensitivities of $18 \mathrm{ng} / \mathrm{L}$ (IL-6) and 10 ng/L (TNF). For the IL-6 ELISA, the correlation coefficient of the linear regression of the standard curve was 0.99 and the intraassay and interassay coefficients of variation were $6.9 \pm 1.2$ and $9.6 \pm 1.0$, respectively. For the TNF ELISA, the correlation coefficient of the linear regression of the standard curve was 0.99 , and the intraassay and interassay coefficients of variation were 6.0 \pm 1.4 and $7.9 \pm 2.0$, respectively.
Protein determination. Total protein content of lung lavage samples was determined using bicinchoninic acid (Pierce Chemical Co., Rockford, IL).

Statistical analysis. Unless stated otherwise, data are expressed as the mean $\pm \mathrm{SD}$. Because there are no satisfactory reference denominators to normalize lung lavage data (30-34) and to compare results of this study with previous reports $(6,8,9,13)$, lung lavage variables are expressed as concentration per volume. Although the secretory component of IgA has recently been suggested as an appropriate reference measurement to correct for dilutional effects of neonatal lung lavage $(35,36)$, it does not represent recovery from the alveolar compartment because it is not secreted by alveolar cells (37) and it has not been evaluated in normal newborn lungs $(35,36)$. Statistical analysis was performed using the Statview II statistical software package (Abacus Concepts, Inc., Berkeley, CA). Intragroup differences over time and intergroup variation for lung lavage variables were first determined by a one-way analysis of variance (28). Specific comparisons of lung lavage variables between groups were done using the Dunnett $t$ test. Correlations were tested using linear regression analysis. A $p$ value of $<0.05$ was considered significant.

\section{RESULTS}

Characteristics of the study population. Of the 30 premature infants with an initial diagnosis of RDS, 19 developed BPD according to study criteria. The clinical characteristics of the three groups are presented in Tables 1 and 2 . There were no statistically significant differences for birth weight or gestational age between the RDS and BPD groups, but the two groups of infants with lung disease were each of significantly lower birth weight and gestational age than the control group (Table 1).

The sex and ethnic distributions of the three groups were similar. There were no differences in prenatal factors except for a higher incidence of preterm labor in the lung disease groups compared with controls (Table 2). There was a significantly higher rate of vaginal delivery, surfactant therapy, and patent ductus arteriosus in the

Table 1. Clinical characteristics of the study population*

\begin{tabular}{lccc}
\hline & $\begin{array}{c}\text { Control } \\
(n=10)\end{array}$ & $\begin{array}{c}\text { RDS } \\
(n=11)\end{array}$ & $\begin{array}{c}\text { BPD } \\
(n=19)\end{array}$ \\
\hline Birth weight $(\mathrm{g})$ & $2102 \pm 882$ & $1221 \pm 462 \dagger$ & $769 \pm 150 \dagger$ \\
Gestational age $(w \mathrm{k})$ & $34.7 \pm 5.1$ & $28.9 \pm 1.7 \dagger$ & $26.2 \pm 1.5 \dagger$ \\
Apgar scores & & & \\
$\quad 1$ min & $5.2 \pm 2.6$ & $4.5 \pm 3.2$ & $4.1 \pm 2.6$ \\
$\quad 5$ min & $8.0 \pm 1.2$ & $6.4 \pm 2.9$ & $6.2 \pm 2.3$ \\
$\quad \begin{array}{l}\text { Ventilatory support } \\
\quad \text { Total days ventilation }\end{array}$ & $14.2 \pm 30.1$ & $11.9 \pm 9.5$ & $51.2 \pm 30.6 \dagger \ddagger$ \\
$\quad$ Supplemental oxygen (d) & $19.0 \pm 30.9$ & $22.8 \pm 15.1$ & $83.0 \pm 67.0 \dagger \ddagger$ \\
$\quad$ Total hospital days & $43.8 \pm 26.5$ & $53.5 \pm 16.9$ & $96.2 \pm 44.8 \dagger \ddagger$ \\
\hline
\end{tabular}

* Data are expressed as mean \pm SD. Total days of ventilation include the sum of days requiring intermittent mandatory ventilation and nasal continuous positive airway pressure.

$\dagger p<0.05$ compared with control group.

$\ddagger p<0.05$ compared with RDS group. 
Table 2. Comparison of prenatal and neonatal factors between the study groups*

\begin{tabular}{|c|c|c|c|c|}
\hline & $\begin{array}{l}\text { Control } \\
(n=10)\end{array}$ & $\begin{array}{c}\text { RDS } \\
(n=11)\end{array}$ & $\begin{array}{c}\text { BPD } \\
(n=19)\end{array}$ & $p$ \\
\hline \multicolumn{5}{|l|}{ Prenatal factors } \\
\hline Preterm labor & $4(40)$ & $8(73)$ & $19(100)$ & 0.001 \\
\hline PROM & 0 & $5(45)$ & $6(32)$ & 0.057 \\
\hline Chorioamnionitis & 0 & $4(36)$ & $5(26)$ & 0.118 \\
\hline Betamethasone & $3(30)$ & $8(73)$ & $9(47)$ & 0.141 \\
\hline Betamimetics & $2(20)$ & $1(9)$ & $8(42)$ & 0.123 \\
\hline Magnesium sulfate & $3(30)$ & $7(64)$ & $14(74)$ & 0.071 \\
\hline \multicolumn{5}{|l|}{ Route of delivery } \\
\hline SVD & $2(20)$ & $2(18)$ & $13(68)$ & 0.007 \\
\hline $\mathrm{C} / \mathrm{S}$ & $8(80)$ & $9(82)$ & $6(32)$ & \\
\hline \multicolumn{5}{|l|}{ Neonatal factors } \\
\hline \multicolumn{5}{|l|}{ Sex } \\
\hline Male & $3(30)$ & $6(55)$ & $13(68)$ & 0.142 \\
\hline Female & $7(70)$ & $5(45)$ & $6(32)$ & \\
\hline \multicolumn{5}{|l|}{ Race } \\
\hline Black & $4(40)$ & $8(73)$ & $15(79)$ & 0.095 \\
\hline White & $6(60)$ & $3(27)$ & $4(21)$ & \\
\hline Surfactant therapy & 0 & $3(27)$ & $14(74)$ & 0.0003 \\
\hline Exosurf & & 2 & 4 & \\
\hline Survanta & & 1 & 10 & \\
\hline PDA & 0 & $2(18)$ & $15(79)$ & 0.0001 \\
\hline Sepsis (late onset) & $4(40)$ & $4(36)$ & $14(74)$ & 0.077 \\
\hline Survival & $9(90)$ & $11(100)$ & $17(89)$ & 0.54 \\
\hline
\end{tabular}

* Data are presented as mean \pm SD with percentages in parentheses. SVD, spontaneous vaginal delivery; $\mathrm{C} / \mathrm{S}$, cesarean section; PDA, patent ductus arteriosus.

BPD group. Decisions concerning the use of exogenous surfactant and the choice of preparation were made by the clinical staff caring for the infants. In all instances, exogenous surfactant was given as rescue therapy at $\geq 2$ $h$ of age. Two of three treated RDS subjects and four of the 14 treated BPD subjects received Exosurf (Burroughs
Wellcome, Research Triangle Park, NC), and the remainder received Survanta (Ross Laboratories, Columbus, $\mathrm{OH}$ ) (Table 2). All infants who were treated with exogenous surfactant were lavaged for the first time at least $6 \mathrm{~h}$ after their first dose of surfactant. The BPD infants received positive pressure ventilation for longer periods than the RDS or control infants $(51.2 \pm 30.6 \mathrm{~d}$, BPD; 11.9 $\pm 9.5 \mathrm{~d}$, RDS; and $14.2 \pm 30.1 \mathrm{~d}$, control). The BPD infants were exposed to supplemental oxygen and were hospitalized for significantly longer periods than the other groups (Table 1).

Cytokine antigenic concentrations and functional activities in lung lavage. There were 149 samples collected from the 40 subjects with a mean number of samples per subject of $4 \pm 2$. In 10 subjects, lavage was not obtained during the first $24 \mathrm{~h}$ because 1 ) the infant was not intubated on $\mathrm{d} 1$ (one control), 2) the investigator was not available ( $n=$ 3 ), or 3) the infant was considered clinically too unstable for the lavage procedure $(n=6)$. Because lavage return was limiting, functional assays were performed first, and any residual fluid was assayed for antigen concentrations. There were 64 and 69 paired functional assays and antigen concentrations for IL-6 and TNF, respectively. There were 88 samples for which both IL- 6 and TNF functional activities were measured.

On the first day of life, IL-6 activity in lung lavage of infants who developed BPD was 15-fold and 6.6-fold higher compared with activities in lavage from control and RDS infants, respectively [control $(n=6), 49.4 \pm$ 17.6; RDS $(n=6), 117.3 \pm 59.6$; BPD $(n=12), 779.5 \pm$ $212.6 \times 10^{3}$ hybridoma units $/ \mathrm{L}$, mean $\pm \mathrm{SEM} ; p=0.02$; Fig. 1]. IL-6 activity remained elevated in BPD lavage samples during the first $2 \mathrm{wk}$, but significantly decreased

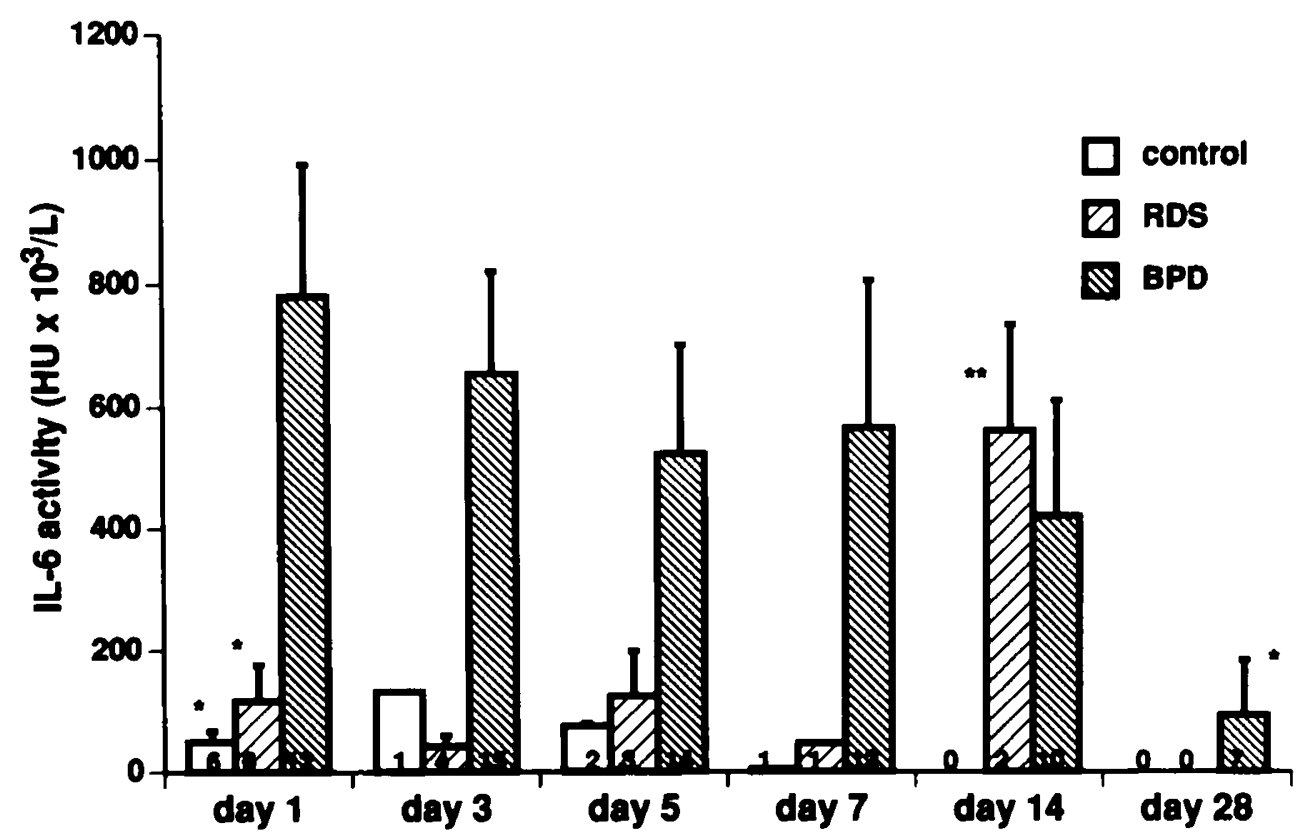

Figure 1. Comparison of functional IL-6 activity in lung lavage of control, RDS, and BPD subjects. IL-6 activity determined by the 7TD1 proliferation assay is expressed as hybridoma units $\times 10^{3} / \mathrm{L}$, mean $\pm \mathrm{SEM}$, with each column labeled with the number of samples assayed. ${ }^{*}, p$ $<0.05$ compared with BPD group $\mathrm{d} 1 .^{* *}, p<0.05$ compared with $\mathrm{d} 1,3$, and 5 within the RDS group. 
by $d 28$. In the few subjects in the control and RDS groups in which lung lavage was analyzed after the first day of life, IL-6 activity remained low. IL- 6 activity and antigen concentration were increased at $14 \mathrm{~d}$ in lavage samples from two RDS infants who were intubated for longer periods than the other infants in the RDS group for apnea (1) and sepsis (1). There were insufficient or unavailable samples from control and RDS infants for determination of IL- 6 activity at $28 \mathrm{~d}$. To confirm that functional activity was caused by IL-6, some samples of BPD lavage were pretreated with anti-IL-6 antiserum, which completely neutralized their activity in the 7TD1 assay (data not shown). In contrast to functional activity, antigenic concentrations of IL- 6 were variable and not significantly different among groups on the first day of life (Table 3).

Functional TNF activity was undetectable in all control samples at all sample times and in the few available RDS samples from $\mathrm{d} 7$ to 28 (Fig. 2). In contrast, detectable but low activity was found in BPD samples from $d$ to $\mathrm{d} 28$ with peak activity in $\mathrm{d}-14$ samples $(90.0 \pm 40.6 \times$ $10^{3} \mathrm{U} / \mathrm{L}$, mean $\pm \mathrm{SEM}$ ). TNF antigen concentrations did not differ significantly among groups on the first day of life. However, in the BPD group, TNF antigen concentrations were significantly higher on d 14 and d 28 compared with samples collected earlier $(p<0.05)$ (Table 3$)$.

There were no differences among groups in the number of recovered cells in lavage (Table 3 ). Cell viability determined by trypan blue exclusion was $70.4 \pm 7.3 \%$. Neutrophils were the predominant inflammatory cells in all groups for the first $3 \mathrm{~d}$ and remained the predominant cell in lavage from BPD infants $\geq 7 \mathrm{~d}$. For the exogenous surfactant-treated infants, the lavage cell counts were higher on d 1 after Exosurf treatment compared with lavage cell counts after Survanta treatment $(9.7 \pm 6.9 \times$
$10^{6}$ versus $2.6 \pm 1.6 \times 10^{6}, p<0.05$ ). There were no apparent relationships between cell counts and IL- 6 or TNF antigen concentrations or activities.

Protein concentration in lavage fluid remained fairly constant over time, and there were no significant differences among the groups (Table 3). Normalization of lung lavage data for protein concentration did not affect differences in antigen concentration or functional activities of IL-6 or TNF (data not shown).

Because the control group was more mature with higher birth weights than the groups with lung disease, regression analyses were performed for the lavage variables with gestational age or birth weight as the dependent variable. TNF antigen concentrations were significantly correlated with gestational age on $\mathrm{d} 1$ and 3 (d $1: r$ $=0.63, p=0.02 ; \mathrm{d} 3: r=0.85, p=0.0005)$ and with birth weight on d 3 ( $r=0.83, p=0.0009$; Table 4). However, TNF antigen concentrations on subsequent days were not significantly correlated with gestational age or birth weight. There were no significant correlations between TNF activity, IL-6 antigen concentration, or IL-6 activity and either gestational age or birth weight (Table 4).

To determine whether abnormalities in functional IL-6 activity on $d 1$ were caused by differences in clinical variables, IL- 6 activity and antigen concentration were correlated with prenatal factors (prolonged rupture of the membranes, chorioamnionitis), delivery route, presence or absence of a patent ductus arteriosus, exogenous surfactant therapy, and survival (Table 5). Although there was a trend toward higher IL-6 activity and antigen concentration associated with chorioamnionitis, the differences were not significant. However, IL-6 activity was 3.7 times higher in lavage on $\mathrm{d} 1$ in the two infants who died because of pulmonary-related causes compared with activities in lavage from all surviving infants (nonsurvi-

Table 3. Comparison of antigen concentrations of IL-6 and TNF, total cell counts, differentials, and total protein in lung lavage from the three groups*

\begin{tabular}{|c|c|c|c|c|c|c|c|}
\hline Variable & Group & d 1 & d 3 & d 5 & d 7 & d 14 & d 28 \\
\hline \multirow[t]{3}{*}{ IL-6 (ng/L) } & Control & $174 \pm 148(7)$ & $420(1)$ & $160 \pm 13(2)$ & (0) & $0(1)$ & $0(1)$ \\
\hline & RDS & $194 \pm 335$ & $97 \pm 137(2)$ & $268 \pm 378(2)$ & $0(1)$ & $580 \pm 820(2)$ & $0(1)$ \\
\hline & BPD & $230 \pm 245(8)$ & $145 \pm 150(11)$ & $213 \pm 179(11)$ & $350 \pm 298(8)$ & $504 \pm 604(8)$ & $447 \pm 466(4)$ \\
\hline \multirow[t]{3}{*}{ TNF (ng/L) } & Control & $535 \pm 795(6)$ & $468(1)$ & $0 \pm 0(2)$ & $0(1)$ & $20 \pm 14(2)$ & $70(1)$ \\
\hline & RDS & $142 \pm 231$ & $0 \pm 0(2)$ & $0(1)$ & $0(1)$ & $0(1)$ & $9(1)$ \\
\hline & BPD & $10 \pm 14(5) \dagger \ddagger$ & $29 \pm 56(9) \dagger \ddagger$ & $16 \pm 23(9) \dagger \ddagger$ & $82 \pm 116(9) \dagger \ddagger$ & $336 \pm 417(5)$ & $341 \pm 412(6)$ \\
\hline \multirow[t]{3}{*}{ Cell count $\left(\times 10^{6}\right)$} & Control & $3.4 \pm 3.0(9)$ & $2.8(1)$ & $4.6 \pm 4.9(2)$ & $1.1 \pm 0.8(2)$ & $5.5 \pm 3.5(2)$ & $1.4(1)$ \\
\hline & RDS & $4.0 \pm 3.4(7)$ & $6.0 \pm 5.7(5)$ & $7.1 \pm 5.8(4)$ & $4.6(1)$ & $8.2 \pm 1.1(2)$ & $7.6(1)$ \\
\hline & BPD & $5.3 \pm 5.8(14)$ & $5.1 \pm 4.9(17)$ & $5.2 \pm 6.1(17)$ & $7.1 \pm 5.1(15)$ & $7.7 \pm 5.1(15)$ & $6.9 \pm 5.9(12)$ \\
\hline \multirow[t]{3}{*}{$\%$ Neutrophils } & Control & $76 \pm 20$ & 98 & $33 \pm 4$ & 8 & $81 \pm 16$ & 96 \\
\hline & RDS & $54 \pm 25$ & $79 \pm 16$ & $49 \pm 30$ & 15 & $61 \pm 26$ & 9 \\
\hline & BPD & $52 \pm 24$ & $53 \pm 25$ & $44 \pm 27$ & $60 \pm 24$ & $63 \pm 25$ & $64 \pm 33$ \\
\hline \multirow[t]{3}{*}{ \% Macrophages } & Control & $23 \pm 20$ & 2 & $67 \pm 4$ & 92 & $19 \pm 16$ & 96 \\
\hline & RDS & $46 \pm 25$ & $21 \pm 16$ & $51 \pm 30$ & 85 & $39 \pm 26$ & 91 \\
\hline & BPD & $48 \pm 24$ & $47 \pm 25$ & $56 \pm 27$ & $40 \pm 24$ & $37 \pm 25$ & $36 \pm 33$ \\
\hline \multirow[t]{3}{*}{ Protein $(\mathrm{mg} / \mathrm{L})$} & Control & $403 \pm 332(9)$ & $900(1)$ & $693 \pm 527(2)$ & $477(1)$ & $628 \pm 788(2)$ & 60 \\
\hline & RDS & $982 \pm 710(7)$ & $440 \pm 396(5)$ & $130 \pm 71(4)$ & $880(1)$ & $240 \pm 226(2)$ & 60 \\
\hline & BPD & $392 \pm 89(14)$ & $360 \pm 277(17)$ & $360 \pm 231(17)$ & $934 \pm 854(15)$ & $581 \pm 587(17)$ & $488 \pm 429(12)$ \\
\hline
\end{tabular}

* Data are presented as the mean $\pm \mathrm{SD}$. The number of lung lavage samples assayed in each group is in parentheses.

$\dagger p<0.05$ compared with BPD d 28 .

$\ddagger p<0.05$ compared with BPD d 14 . 


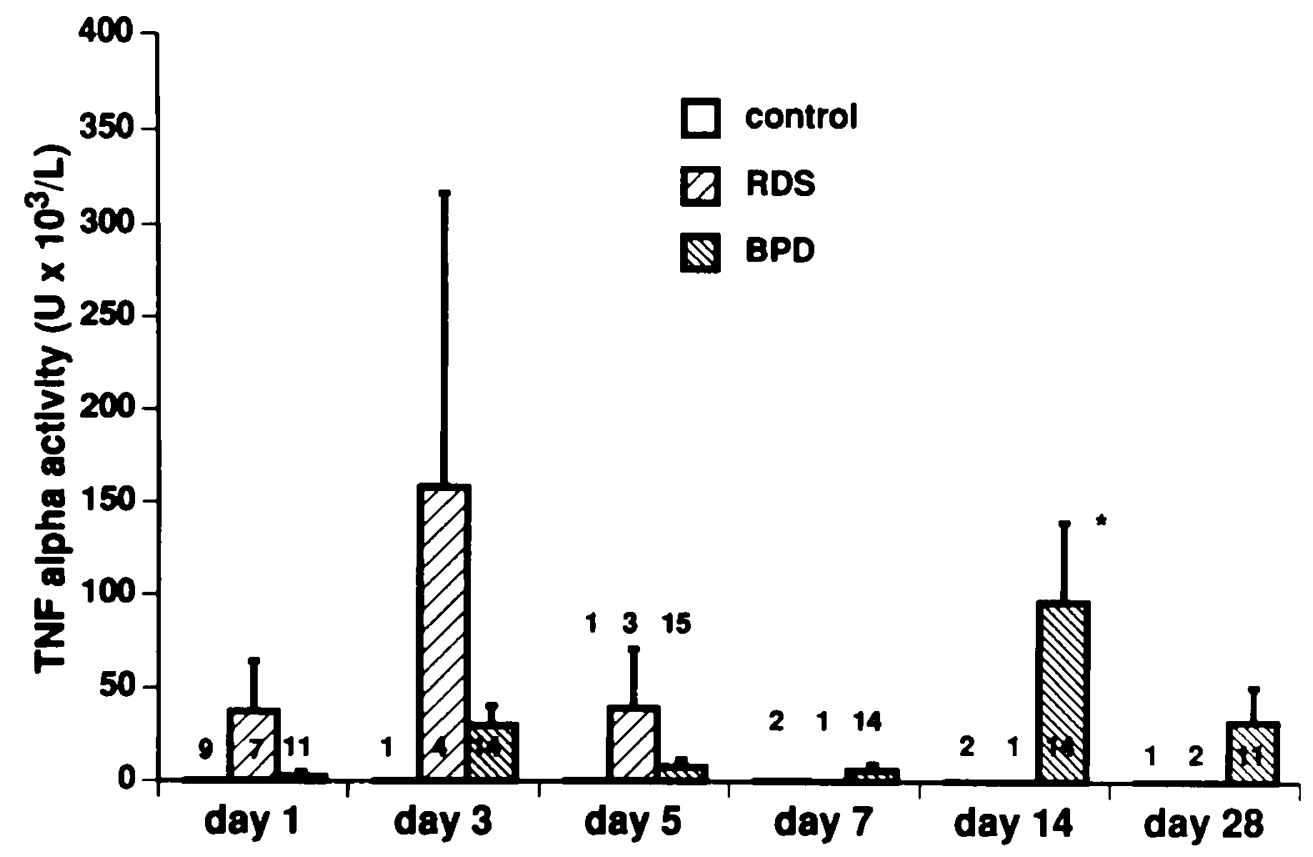

Figure 2. Comparison of functional TNF activity in lung lavage of control, RDS, and BPD subjects. TNF activity determined by the L929 cytotoxicity assay is expressed as units $\times 10^{3} / \mathrm{L}$, mean $\pm \mathrm{SEM}$, with each column labeled with the number of samples assayed. ${ }^{*}, p<0.05$ compared with d $1,3,5$, and 7 within the BPD group.

vors, $1334 \pm 472$; survivors, $364 \pm 588 \times 10^{3}$ hybridoma units $/ \mathrm{L}, p<0.05)$. There was no apparent effect of surfactant therapy or other clinical variables on lung lavage variables.

On d 1 of life, there were no significant differences among groups for maximal ventilatory settings (fraction of inspired oxygen, peak inspiratory pressure, positive end expiratory pressure, and mean airway pressure), but the BPD infants had significantly lower dynamic compliance $(5.3 \pm 0.5 \mathrm{~mL} / \mathrm{kPa} / \mathrm{kg})$ than RDS infants or controls $(9.3 \pm 2.2$ and $7.8 \pm 1.9 \mathrm{~mL} / \mathrm{kPa} / \mathrm{kg}$, respectively) consistent with more severe initial lung disease. The differences in dynamic compliance between RDS and control groups were not significant. As previously observed by other investigators $(38,39)$, the BPD infants had persistently low compliance and elevated resistance from $d 7$ through $d 28$. However, there were no correlations between ventilatory settings or pulmonary mechanics and cytokine activities or antigen concentrations.

Table 4. Correlations between lung lavage variables

\begin{tabular}{llll}
\hline \multicolumn{1}{c}{ Variable 1 } & \multicolumn{1}{c}{ Variable 2 } & $r$ value & $p$ value \\
\hline Gestational age & IL-6 (activity) & 0.38 & 0.07 \\
Birth weight & IL-6 (activity) & 0.312 & 0.14 \\
Gestational age & TNF (ELISA) d 1 & 0.63 & 0.02 \\
Birth weight & TNF (ELISA) d 1 & 0.51 & 0.06 \\
Gestational age & TNF (activity) d 1 & 0.05 & 0.79 \\
Birth weight & TNF (activity) d 1 & 0.05 & 0.79 \\
IL-6 (ELISA) & IL-6 (activity) & 0.08 & 0.55 \\
TNF (ELISA) & TNF (activity) & 0.42 & 0.0003 \\
IL-6 (ELISA) & TNF (activity) & 0.5 & 0.0001 \\
TNF (ELISA) & IL-6 (activity) & 0.09 & 0.53 \\
IL-6 (activity) & TNF (activity) & 0.28 & 0.0074 \\
\hline
\end{tabular}

\section{DISCUSSION}

In the present study, functional IL-6 activity in lung lavage from infants who developed BPD was 15 -fold and 6.6-fold higher than activities in lavage from controls and infants with self-limited RDS on the first day and remained elevated during the first 2 wk of life. In contrast to functional activity, there were no differences in antigenic IL-6 in d 1 lavage fluids among the BPD, RDS, and control groups (Table 3 ). The higher specific activity of IL-6 in d 1 lung lavage from the BPD group suggests that pathways for inactivating or inhibiting IL-6 (40) that may be present in the lungs of self-limited RDS and control patients may be deficient in patients who subsequently develop BPD. In addition, the lack of correlation be-

Table 5. Associations of recoverable IL-6 on d 1 of life with clinical variables*

\begin{tabular}{llll}
\hline \multicolumn{1}{c}{ Variable } & Present & $\begin{array}{c}\text { IL-6 activity } \\
(\mathrm{HU} / \mathrm{mL})\end{array}$ & $\begin{array}{c}\text { Antigenic IL-6 } \\
(\mathrm{ng} / \mathrm{L})\end{array}$ \\
\hline PROM & Yes & $498 \pm 1025$ & $194 \pm 194$ \\
Nohorioamnionitis & Yes & $612 \pm 980$ & $203 \pm 52$ \\
& No & $371 \pm 481$ & $188 \pm 54$ \\
Delivery route & NSVD & $393 \pm 396$ & $194 \pm 196$ \\
PDA & C/S & $470 \pm 811$ & $207 \pm 236$ \\
& Yes & $623 \pm 506$ & $262 \pm 92$ \\
Surfactant & No & $316 \pm 678$ & $163 \pm 59$ \\
& Yes & $478 \pm 525$ & $256 \pm 225$ \\
Survival & No & $392 \pm 719$ & $181 \pm 217$ \\
& Yes & $364 \pm 588$ & $189 \pm 49$ \\
& No & $1334 \pm 472 \dagger$ & $303 \pm 303$ \\
\hline
\end{tabular}

* Data are presented as mean \pm SD. HU, hybridoma units; NSVD, nomal spontaneous vaginal delivery; $\mathrm{C} / \mathrm{S}$, cesarean section; PDA, patent ductus arteriosus.

$\dagger p<0.05$ compared with survival group. 
tween antigen concentration and functional activity of IL-6 demonstrates the importance of measuring bioassays of cytokines in biologic fluids. Cytokine antigen may be detectable by ELISA, but the protein may be degraded or inactivated by bound inhibitors or soluble receptors $(40-43)$. In contrast to IL-6, TNF activity in lung lavage was low in all groups on $\mathrm{d} 1$ but increased by $\mathrm{d} 14$ of age in lavage of BPD infants. These findings suggest that differences in the activities of these cytokines, particularly IL-6, may be important in the regulation of lung inflammation and the pathogenesis of BPD. We speculate that the early increase in IL- 6 activity in the BPD infants may be a response to the severity of the initial lung injury.

In this study, there were technical limitations such as variable dilutional effects of the lavage procedure on assay measurements, availability of appropriate controls, and ethical concerns about lavaging healthy, nonintubated infants. For all assays, there were large standard deviations within groups. This most likely reflects biologic variability due to differences in severity of lung injury and differences in the complex host response, but dilutional effects of the lavage procedure may have contributed. Unfortunately, an appropriate reference denominator to correct for dilutional effects of lavage has not been described (30-34). However, we doubt that the large differences in IL- 6 activity among groups on $\mathrm{d} 1 \mathrm{can}$ be explained by differential dilution. Inasmuch as the same volume was used for lavage in all subjects, a greater dilution should be expected for the smaller infants, which would minimize differences between the low birth weight BPD infants and the larger control infants, but higher IL-6 activities were measured in the BPD group than in the control group. Although it would be desirable to have control subjects with similar birth weight and gestational age as the study subjects, it would be unethical to intubate and lavage the lungs of healthy low-birth-weight infants for research purposes because of the serious risks of these procedures.

IL-6 is a multifunctional cytokine with both potential local and systemic effects (44). It induces production of hepatic acute-phase reactant proteins, stimulates $B$ cell differentiation and $T$ cell activation (44), and increases vascular permeability in vitro (45). IL-6 concentrations were elevated in amniotic fluid of women with preterm labor complicated by intraamniotic infection (15). Recently, Grigg et al. (18) reported an association of increased antigenic IL- 6 concentrations in lung lavage of preterm infants on the first day of life and prolonged rupture of membranes. However, functional activity was not measured and the relationship of IL-6 to the development of BPD was not described (18). In the present study, we did not find significant differences in IL-6 activity or antigenic concentrations in lung lavage of infants from pregnancies complicated by chorioamnionitis compared with activity and levels in lavage of infants from pregnancies without clinical signs of chorioamnionitis (Table 5). The differences in study results may be caused, in part, by differences in study populations or by institutional differences in obstetrical management of PROM. For example, in our institution, maternal antibiotic prophylaxis is used commonly for PROM. Antibiotic therapy may suppress bacteria that induce cytokine release.

The source of IL- 6 retrieved from the airways cannot be determined from this study. Potential sources include 1) lung cells (macrophages, fibroblasts, epithelial and endothelial cells), 2) alveolar leak of plasma proteins including cytokines, and 3) aspirated amniotic fluid. Although in vitro studies suggest that IL-6 production by cultured monocytes from preterm infants is depressed compared with synthesis by monocytes from term infants $(18,46,47)$, other in vivo studies suggest that preterm infants are capable of IL-6 synthesis (17). Macrophages that were detected in lung lavage as early as $d 1$ in the infants with lung disease may be a source of the greatly elevated IL-6 activity found in BPD infant lavage on the first day of life. Because plasma samples were not obtained in this study, it is not possible to determine the relative contribution of locally released factors versus plasma-derived factors to the balance of cytokine activities. However, inasmuch as plasma levels of IL-6 are low in newborns in the absence of sepsis (48), it is unlikely that circulating IL- 6 contributed significantly to the IL-6 levels in the lungs of these infants. The similar patterns of IL-6 expression in intraamniotic fluid in preterm labor and preterm infant lung lavage suggest a possible common pathway of cytokine involvement in initiating preterm labor and neonatal lung injury. Correlations of amniotic fluid IL-6 concentration and activity with infant lung lavage levels will be necessary to determine the relationship of cytokine-mediated labor and neonatal lung inflammation.

TNF antigen concentrations of samples from $d 1$ and 3 , but not concentrations of samples from subsequent days, significantly correlated with gestational age and birth weight (Table 4). This suggests that early TNF synthesis may be development dependent, but other factors affect TNF expression beyond the first few days of life. In contrast, TNF activity, as well as IL-6 antigen concentration and IL- 6 activity did not correlate with either gestational age or birth weight. Therefore, the differences in IL-6 activity among groups were not caused solely by maturational differences.

TNF is a potent inducer of IL- 6 expression by inflammatory and structural cells (49-52). IL-6 inhibits release of TNF by macrophages (21), thereby forming a negative feedback loop, which may limit inflammation. Intratracheal IL-6 blocked lipopolysaccharide-induced lung injury in rabbits (19). Soluble inhibitors of TNF (41-43) and IL-6 (40) may further modulate the interaction between these cytokines by decreasing the availability of functional TNF or IL-6. In the BPD group, antigenic TNF levels were low on d 1 (Table 3 ) when IL- 6 activity was highest (Fig. 1). TNF levels subsequently rose in the BPD patients, with the highest levels from d 14 to $d 28$, when 
IL-6 activity in lung lavage decreased. However, by regression analysis, there was a significant but weak positive correlation between TNF and IL-6 activity in paired samples $(r=0.28, p=0.007)$. The lack of a strong negative correlation in paired samples suggests that there is not an inhibitory feedback mechanism between IL-6 and TNF in the neonatal lung. Alternatively, a relationship between IL- 6 and TNF may be obscured by complex interactions with other cytokines, other inflammatory mediators, and pharmacologic agents. The interactions between these two cytokines, if any, will need to be further defined by in vitro studies of inflammatory cells from neonatal lungs.

Because we observed an initial increase in IL-6 activity and a late increase in TNF in lung lavage of BPD infants, we propose that the early elevated IL-6 may be a response to severe lung injury and hence may be an important early marker of BPD, whereas TNF may contribute to chronic inflammation in established BPD. Further in vestigation is needed to determine how the complex interactions of these and other cytokines influence the course of neonatal lung injury and to determine how therapeutic agents, including exogenous surfactant, modulate the cytokine inflammatory cascade.

\section{REFERENCES}

1. Hennes HM, Lee MB, Rimm AA, Shapiro DL 1991 Surfactant replacement therapy in respiratory distress syndrome. Am J Dis Child 145:102-1(14

2. Coalson JJ, Kuehl TJ, Prihoda TJ, de Lemos RA 1988 Diffuse alveolar damage in the evolution of bronchopulmonary dysplasia in the baboon. Pediatr Res 24:357-366

3. O'Brodovich HM, Mellins RB 1985 Bronchopulmonary dysplasia: unresolved neonatal acute lung injury. Am Rev Respir Dis 132:694-709

4. Merritt TA, Puccia JM, Stuard ID 1981 Cytologic evaluation of pulmonary effluent in neonates with respiratory distress syndrome and bronchopulmonary dysplasia. Acta Cytol 25:631-639

5. Ogden BE, Murphy S, Saunders GC, Johnson JD 1983 Lung lavage of newborns with respiratory distress syndrome: prolonged neutrophil influx is associated with bronchopulmonary dysplasia. Chest 83:31S-33S

6. Speer CP, Ruess D, Harms K, Herting E, Gefeller O 1993 Neutrophil elastase and acute pulmonary damage in neonates with severe respiratory distress syndrome. Pediatrics 91:794-799

7. Jackson JC, Chi EY, Wilson CB, Truog WE, Teh EC, Hodson WA 1987 Sequence of inflammatory cell migration into lung during recovery from hyaline membrane disease in premature newborn monkeys. Am Rev Respir Dis 135:937-940

8. Groneck P, Reuss D, Gotze-Speer B, Speer CP 1993 Effects of dexamethasone on chemotactic activity and inflammatory mediators in tracheobronchial aspirates of preterm infants at risk for chronic lung disease. J Pediatr 122:938944

9. Yoder MC, Chua R, Tepper R 1991 Effect of dexamethasone on pulmonary inflammation and pulmonary function of ventilator-dependent infants with bronchopulmonary dysplasia. Am Rev Respir Dis 143:1044-1048

10. Merritt TA, Cochrane CG, Hallman M, Holcomb KE, Strayer D, Mannino F, Edwards DK, Gluck L 1983 Reduction of lung injury by human surfactan treatr.ent in respiratory distress syndrome. Chest 83:27S-30S

11. Rosenfeld W, Concepcion L, Evans H, Jhaveri R, Sahdev S, Zabaleta I 1986 Serial trypsin inhibitory capacity and ceruloplasmin levels in prematures a risk for bronchopulmonary dysplasia. Am Rev Respir Dis 134:1229-1232

12. Stenmark KR, Eyzaguirre M, Westcott JY, Henson PM, Murphy RC 1987 Potential role of eicosanoids and PAF in the pathophysiology of bronchopulmonary dysplasia. Am Rev Respir Dis 136:770-772

13. Viscardi RM, Broderick K, Sun C-CJ, Yale-Loehr A, Hessamfar A, Taciak V, Burke KC, Koenig KB, Idell S 1992 Disordered pathways of fibrin turnover in lung lavage of premature infants with respiratory distress syndrome. Am Rev Respir Dis 146:492-499

14. Kelly J 1991 Cytokines of the lung. Am Rev Respir Dis 141:765-788

15. Romero R, Avial C, Santhanam U, Sehgal PB 199) Amniotic fluid interleukin 6 in preterm labor. J Clin Invest 85:1392-1400)

16. Romero R, Manogue KR, Mitchell MD, Wu YK, Oyarzun E, Hobbins JC, Cerami A 1989 Infection and labor: IV. cachectin-tumor necrosis factor in the amniotic fluid of women with intraamniotic infection and preterm labor. Am J Obstet Gynecol 161:336-341
17. De Bont ESJM, Martens A, Van Raan J, Samson G, Fetter WPF, Okken A. De Leij LHFM 1993 Tumor necrosis factor- $\alpha$, interleukin-1 $\beta$, and interleukin-6 plasma levels in neonatal sepsis. Pediatr Res 33:380-383

18. Grigg JM, Barber A, Silverman M 1992 Increased levels of bronchoalveolar lavage fluid interleukin- 6 in preterm ventilated infants after prolonged rupture of membranes. Am Rev Respir Dis 145:782-786

19. Ulich TR, Yin S, Guo K, Yi ES, Remick D, del Castillo J 1991 Intratracheal injection of endotoxin and cytokines. 11. Interleukin-6 and transforming growth factor beta inhibit acute inflammation. Am J Pathol 138:1097-1101

20. Barton BE, Jackson JV 1993 Protective role of interleukin 6 in the lipopolysaccharide-galactosamine septic shock model. Infect Immun 61:14961499

21. Aderka D, Le J, Vilcek J 1989 IL-6 inhibits lipopolysaccharide-induced tumo necrosis factor production in cultured human monocytes, U937 cells, and in mice. J Immunol 143:3517-3523

22. Nordan RP, Pumphrey JG, Rudikoff S 1987 Purification and $\mathrm{NH}_{2}$-terminal sequence of a plasmacytoma growth factor derived from the murine macrophage cell line P3888D1. J Immunol 139:813-817

23. Bancalari E, Abdenour GE, Feller R, Gannon J 1979 Bronchopulmonary dysplasia: clinical presentation. J Pediatr 95:819-829

24. Northway WH, Rosan RC. Porter DY 1967 Pulmonary disease following respirator therapy of hyaline-membrane disease. N Engl J Med 276:357368

25. Edwards DK, Colby TV, Northway WH 1979 Radiographic-pathologic correlation in bronchopulmonary dysplasia. J Pediatr 95:834-841

26. Bhutani KK. Silveri EM, Abbasi S, Shafer TH 1988 Evaluation of neonatal pulmonary mechanics and energetics: a two factor least mean square analysis. Pediatr Pulmonol 4:150-158

27. Gosset P, Lassalle P, Vanhee D, Wallaert B, Aets C, Voisin C, Tonnel A-B 1991 Production of tumor necrosis factor- $\alpha$ and interleukin- 6 by human alveolar macrophages exposed in vitro to coal mine dust. Am J Respir Cell Mol Biol 5:431-436

28. Jesty J, Godfrey HP 1986 Parlin, a general microcomputer program for parallel-line analysis of bioassays. Am J Clin Pathol 85:485-489

29. Hasday JD, Shah EM, Lieberman A 1990) Macrophage tumor necrosis factor- $\alpha$ release is induced by contact with some tumors. J Immunol 145:371-379

30. Richter AM, Abboud RT, Johal SS 1986 Methylene blue decreases the functional activity of alpha-1-protease inhibitor in bronchoalveolar lavage. Am Rev Respir Dis 134:326-327

31. Marcy TW, Merrill WW, Rankin JA, Reynolds HY 1987 Limitations of using urea to quantify epithelial lining fluid recovered by bronchoalveolar lavage. Am Rev Respir Dis 135:1276-1280

32. Ward C, Duddridge M, Fenwich J, Williams S, Gardiner PV, Hendrick DJ, Walters EH 1992 The origin of water and urea sampled at bronchoalveolar lavage in asthmatic and control subjects. Am Rev Respir Dis 146:444-447

33. Von Wichert PV, Joseph K, Muller B, Franck WM 1993 Quantitation of intraalveolar fluid. Am Rev Respir Dis 147:148-152

34. Berberich MA 1993 NHBLI Workshop summary. Assessment of lung function and dysfunction in studies of infants and children. Am Rev Respir Dis 148:1105-1108

35. Watts C, Bruce M 1992 Secretory component for IgA is a more valid reference protein than albumin in preterm infants. Am Rev Respir Dis 145:340A(abstr)

36. Watts CL, Fanaroff AA, Bruce MC 1992 Elevation of tibronectin levels in lung secretions of infants with respiratory distress syndrome and development of bronchopulmonary dysplasia. J Pediatr 120:614-620

37. Takemura TY 1985 Distribution of secretory component and immunoglobulins in the developing lung. Am Rev Respir Dis 131:125-130

38. Goldman SL, Gerhardt T, Sonni R, Feller R, Hehre D, Tapia JL, Bancalari E 1983 Early prediction of chronic lung disease by pulmonary function testing. J Pediatr 102:613-616

39. Motoyama EK, Fort MD, Klesh KW, Mutich RL, Guthrie RD 1987 Early onset of airway reactivity in premature infants with bronchopulmonary dysplasia. Am Rev Respir Dis 136:50-57

40. Soliman DM, Twigg HLI 1992 Cigarette smoking decreases bioactive interleukin-6 secretion by alveolar macrophages. Am J Physiol 263:L471-L478

41. Gatanaga T, Hwang C, Kohr W, Cappuccini F, Lucci III JA, Jeffes EWB, Lentz R, Tomich J, Yamamoto RS, Granger GA 199) Purification and characterization of an inhibitor (soluble tumor necrosis factor receptor) for tumor necrosis factor and lymphotoxin obtained from the serum ultrafiltrates of human cancer patients. Proc Natl Acad Sci USA 87:8781-8784

42. Engelmann H, Novick D, Wallach D 1990 Two tumor necrosis factor-binding proteins purified from human urine. Evidence for immunological crossreactivity with cell surface tumor necrosis factor receptors. J Biol Chem 265:1531-1536

43. Austgulen R, Liabakk NB, Lien E, Espevik T 1993 Increased levels of soluble tumor necrosis factor- $\alpha$ receptors in serum from pregnant women and in serum and urine samples from newborns. Pediatr Res 33:82-86

44. Kishimoto T 1989 The biology of interleukin-6. Blood 74:1-10

45. Maruo N, Morita I, Shirao M, Murota S 1992 IL-6 increases endothelial permeability in sitro. Endocrinology 131:710-714

46. Liechty KW, Koenig JM, Mitchell MD, Romero R, Christensen RD 1991 Production of interleukin- 6 by fetal and maternal cells in vivo during intraamniotic infection and in vitro after stimulation with interleukin-1. Pediatr Res $29: 1-4$ 
47. Yachie A, Takano N, Ohta $K$, Uehara $T$, Fujita $S$, Miyawaki T, Taniguchi $N$ 1992 Defective production of interleukin- 6 in very small premature infants in response to bacterial pathogens. Infect Immun 60:749-753

48. Miller LC, Isa S, LoPreste G, Schaller JG, Dinarello CA 1990 Neonatal interleukin-1 $\beta$, interleukin-6, and tumor necrosis factor: cord blood levels and cellular production. J Pediatr 117:961-965

49. Shalaby MR, Waage A, Espevik T 1989 Cytokine regulation of interleukin 6 production by human endothelial cells. Cell Immunol 121:372-382

50. Cohen-Kaminsky S, Delattre R-M, Devergne O, Rouet P, Gimond D, Berrih-
Aknin S, Galanaud P 1991 Synergistic induction of interleukin-6 production and gene expression in human thymic epithelial cells by LPS and cytokines. Cell Immunol 138:79-93

51. Slack JL, Nemunaitis J, Andrews III DF. Singer JW 1990 Regulation of cytokine and growth factor gene expression in human bone marrow stromal cells transformed with simian virus 40 . Blood 75:2319-2327

52. Matsuguchi, T, Okamura, S, Kawasaki, C. Niho, Y 1990 Production of interleukin 6 from human liver cell lines: production of interleukin 6 is not concurrent with the production of $\alpha$-fetoprotein. Cancer Res 50:7457-7459 